Clinical Research Paper

\title{
Negative to positive lymph node ratio is a superior predictor than traditional lymph node status in stage III colorectal cancer
}

\author{
Qingguo $\mathrm{Li}^{1,2, *}$, Lei Liang ${ }^{1,2, *}$, Huixun $\mathrm{Jia}^{2,3}$, Xinxiang $\mathrm{Li}^{1,2}$, Ye $\mathrm{Xu}^{1,2}$, Ji Zhu ${ }^{3,4}$ and \\ Sanjun $\mathrm{Cai}^{1,2}$ \\ ${ }^{1}$ Department of Colorectal Surgery, Fudan University Shanghai Cancer Center, Shanghai, China \\ 2 Department of Oncology, Shanghai Medical College, Fudan University, Shanghai, China \\ ${ }^{3}$ Center for Biomedical Statistics, Fudan University Shanghai Cancer Center, Shanghai, China \\ ${ }^{4}$ Department of Radiation Oncology, Fudan University Shanghai Cancer Center, Shanghai, China \\ * These authors have contributed equally to this work \\ Correspondence to: Sanjun Cai, email: caisanjun_sh@163.com \\ Ji Zhu, email: leo.zhu@126.com
}

Keywords: colorectal cancer; surgical resection; prognosis analysis; lymph node ratio

Received: December 23, $2015 \quad$ Accepted: July 14,2016 Published: July 24, 2016

\section{ABSTRACT}

Negative lymph node counts has recently attracted attention as a prognostic indicator in colorectal cancer (CRC). But little is known about prognostic significance of negative to positive lymph node ratio (NPR) in CRC. Our aim was to determine impact of NPR on oncological outcomes in patients with stage III CRC. This retrospective study included 2,256 patients with stage III CRC under curative resection at Fudan university Shanghai cancer center. Kaplan-Meier methods and multivariable Cox regression models were built for the analysis of survival outcomes and risk factors. Accuracy of the NPR was assessed with the Harrell's concordance-index(C-index). $X$-tile program identified 2.38 or $0.55 / 2.38$ as the optimal cutoff value for NPR to divide the cohort into high/low risk or high/middle/low risk subsets in terms of CRC cause specific survival (CCSS). In a multivariate analysis, NPR was significant independent prognostic factors for CCSS $(P<0.05)$, notably, $N$ classification was not an independently prognostic factor $(P>0.05)$. Further analysis found NPR could give detailed prognostic classification for both $\mathrm{N} 1$ and $\mathrm{N} 2$ stage $(P<0.05)$. Interestingly, patients in N2+ NPR > 2.38 stage have similar survival outcome with N1+ NPR > 2.38 stage $(x 2=0.030, P=0.863)$, and better than those at N1+ NPR $\leq 2.38$ and N2+ NPR $\leq 2.38$ stage $(P<0.001)$. The $\mathrm{TN}_{\mathrm{NPR}} \mathrm{M}$ stage was more accurate for predicting CCSS ( $C$-index $=0.659)$ than current TNM stage system $(C$-index $=0.628)(P<0.001)$. Collectively, NPR was an independent prognostic factor for stage III CRC patients, it could provide more accurate prognostic information than the current node stage system.

\section{INTRODUCTION}

Colorectal cancer (CRC) is one of the most common cancer with its incidence and mortality both ranked third among all malignancies worldwide [1]. In China, as the life style changed, the incidence rate of CRC has grown steadily. The rate of CRC increased as much as 4.2\% per year from 1973 to 1993 in Shanghai, and it ranked as the second most common of cancer related deaths now [2,3].Surgical resection represents optimal approach for people with localized CRC, and to guarantee accurate tumor staging, a benchmark of at least 12 lymph nodes (LNs) retrieval has been recommended by the International Union Against Cancer and the 
American Joint Committee on Cancer (AJCC) since 2000. Theoretically, the survival of CRC patients is improved by removing more LNs. Previous researchers have indicated that the increased LNs retrieval is correlated with the reduced incidence of recurrence and tumor related death in patients with stage II CRC cancer [4-6]. However, debate exists regarding the clinical value of increased LN retrieval in stage III CRC. Le Voyer et al reported that there was an $23 \%$ increase in the 5-year overall survival if more than 40 LNs were retrieved rather than less than 10 LNs count for patients with N1 stage colon cancer; and in patients with N2 stage, the 5-year overall survival rates following analysis of $>35$ and $<35$ LNs were $71 \%$ and $51 \%$, respectively [7]. Vather et al showed that the LNs counts in stage III patients who died or were alive within 5 years was 13.1 vs 14.8, respectively, and this difference was statistically significant [8]. Chen et al. demonstrated that the median survival times for colon cancer patients with 1-7, 8-14 and $\geq 15 \mathrm{LN}$ retrieval were 46, 52 and 67 months, respectively [9]. However, several studies have not demonstrated a similar correlation between LNs counts and survival in stage III CRC [5, 10-12]. The total number of LNs (TLN) retrieved comprises both positive and negative LNs (NLNs) in stage III patients, so the relationship between TLNs and prognosis is confounded by the prognostic effect of the number of positive LNs (PLNs). The concept of NLN counts has recently attracted attention as a prognostic indicator in various cancer. [1316]. Our previous study also indicated that NLNs was an independent predictor in stage III rectal cancer [17]. It is reasonable to conjecture that negative to positive lymph node ratio (NPR) could be an important predictor in CRC. The purpose of present study was to investigate the prognostic value of NPR in patients with stage III CRC.

\section{RESULTS}

\section{Identification of NPR cut-off points}

Patients' clinicopathological parameters are demonstrated in Table 1. A total of 2,256 eligible patients were included in this study during the 10-year period, including 1,347 male and 929 female. The median age at diagnosis was 58 years old (Inter quartile range, IQR 4968). There were 1,296 patients with N1 stage and 960 with N2 stage. The median number of LNs counts, positive LNs number, negative LNs, and NPR were 15.0 (IQR 12-19), 3 (IQR 2-6), 11(IQR 7-15), and 4.00 (IQR 1.50-9.00), respectively. Median follow-up time for present study cohort was 55 months. The 5-year CCSS was $69.0 \%$.

$\mathrm{X}$-tile program identified 2.38 as the optimal cutoff value for NPR with the maximum log-rank statistical value 118.677 to divide patients into high and low risk, and cutoff $0.55,2.38$ to divide patients into high, middle and low risk. (Figure 1).

\section{Prognostic value of the NPR}

Since the N classification and NPR are both LN staging system, then we classified the patients into two risk subgroups according to NPR cutoff, $\mathrm{N}_{\mathrm{NPR}} 1$ ( > 2.38), $\mathrm{N}_{\mathrm{NPR}} 2(\leq 2.38)$, or three risk subgroups $\mathrm{N}_{\mathrm{NPR}} 1(>2.38)$, $\mathrm{N}_{\mathrm{NPR}} 2(0.55-2.38), \mathrm{N}_{\mathrm{NPR}} 3(\leq 0.55)$, denoted as the $\mathrm{N}_{\mathrm{NPR}}$ classification system, to distinguish from traditional $\mathrm{N}$ stage. Multivariate Cox regression analysis showed that age, tumor differentiation, $\mathrm{T}$ stage, and $\mathrm{N}_{\mathrm{NPR}}$ stage had a significant correlation with CCSS $(P<0.05)$ (Table 2). A higher NPR (for two classifications, $\mathrm{N}_{\mathrm{NPR}} 2$, hazard ratio [HR] 0.428; 95\% confidence interval [CI] 0.315-0.582, $P$ $<0.001$; for three classifications, $\mathrm{N}_{\mathrm{NPR}} 2$, HR $0.607,95 \% \mathrm{CI}$ $0.465-0.793, \mathrm{~N}_{\mathrm{NPR}} 3$, HR $0.284,95 \%$ CI $0.195-0.415, P<$ $0.001, \mathrm{~N}_{\mathrm{NPR}} 1$ as reference) demonstrated a protective effect on survival. Notably, $\mathrm{N}$ classification was not an independently prognostic factor in multivariate Cox regression analysis $(P>0.05)$ (Table 2$)$.

\section{Further analysis for the prognostic value of $\mathrm{N}_{\mathrm{NPR}}$ stage according $\mathbf{N}$ classification}

We then made further subgroup analysis according to each $\mathrm{N}$ stage to determine the effect of $\mathrm{N}_{\mathrm{NPR}}$ stage on CCSS. Specifically, for N1 patients, there was an absolute $26.7 \%$ increase in 5-year CCSS if NPR $>2.38$ were analyzed than those patients of $\leq 2.38(49.9 \%$ VS 76.6\%, $P<0.001$ ) (Table 3) (Figure 2). For N2 patients, the 5-year CCSS for CRC patients at $\mathrm{N}_{\mathrm{NPR}} 1, \mathrm{~N}_{\mathrm{NPR}} 2, \mathrm{~N}_{\mathrm{NPR}} 3$ stage were $38.9 \%, 62.8 \%$ and $77.3 \%$, respectively $(P<0.001)$, the 5 -year CCSS was even two-folds in $\mathrm{N}_{\mathrm{NPR}} 3$ stage than that of $\mathrm{N}_{\mathrm{NPR}} 1$ stage(Table 3, Figure 2). In multivariate analysis, the $\mathrm{N}_{\mathrm{NPR}}$ stage were all validated as independent prognostic factors in both N1 and N2 stage patients. $(P<$ $0.05)$ (Table 3)

\section{Combined analysis of $\mathrm{N}$ stage and $\mathrm{N}_{\mathrm{NPR}}$ stage}

In the above survival analyses, the patients in N2 stage with NPR $>2.38$ exhibited a good 5-year CCSS than patients in N1 stage with NPR $\leq 2.38$ (Table 3). Then we made combined analysis of $\mathrm{N}$ stage and $\mathrm{N}_{\mathrm{NPR}}$ stage to divide the patients into four subgroups, $\mathrm{N} 1+\mathrm{N}_{\mathrm{NPR}} 1, \mathrm{~N} 1+$ $\mathrm{N}_{\mathrm{NPR}} 2, \mathrm{~N} 2+\mathrm{N}_{\mathrm{NPR}} 1$, and $\mathrm{N} 2+\mathrm{N}_{\mathrm{NPR}} 2$.

Five-year CCSS were 49.9\%, 76.6\%, 55.0\%, 77.3\% for $\mathrm{N} 1+\mathrm{NPR} \leq 2.38, \mathrm{~N} 1+\mathrm{NPR}>2.38, \mathrm{~N} 2+\mathrm{NPR} \leq 2.38$, $\mathrm{N} 2+\mathrm{NPR}>2.38$ stage, respectively. Notably, patients in $\mathrm{N} 2+\mathrm{NPR}>2.38$ stage have similar survival outcome with $\mathrm{N} 1+\mathrm{NPR}>2.38$ stage $(\chi 2=0.030, P=0.863)$, and better 
Table 1: Clinicopathological characteristics and Kaplan-Meier CCSS analysis of colorectal cancer patients with lymph nodes involvement in Fudan University Shanghai Cancer Center

\begin{tabular}{|c|c|c|c|c|}
\hline Characteristic & No. & 5-year CCSS & Log-rank $\chi^{2}$ & $P$ value \\
\hline Primary Site & & & 0.317 & 0.574 \\
\hline colon & 985 & $69.2 \%$ & & \\
\hline rectum & 1271 & $67.9 \%$ & & \\
\hline Sex & & & 1.128 & 0.288 \\
\hline male & 1347 & $68.8 \%$ & & \\
\hline female & 929 & $68.0 \%$ & & \\
\hline Age & & & 7.827 & 0.005 \\
\hline$\leq 60$ & 1283 & $72.7 \%$ & & \\
\hline$>60$ & 973 & $63.9 \%$ & & \\
\hline Pathological grading & & & 59.018 & $<0.001$ \\
\hline Well/ Moderate & 1475 & $73.0 \%$ & & \\
\hline Poor/ Anaplastic & 686 & $58.4 \%$ & & \\
\hline Unknown & 95 & $66.5 \%$ & & \\
\hline Histological Type & & & 6.154 & 0.013 \\
\hline Adenocarcinoma & 1876 & $69.0 \%$ & & \\
\hline Mucinous/Signet ring cell & 380 & $66.1 \%$ & & \\
\hline T stage & & & 47.049 & $<0.001$ \\
\hline $\mathrm{T} 1$ & 26 & $89.1 \%$ & & \\
\hline $\mathrm{T} 2$ & 209 & $82.0 \%$ & & \\
\hline $\mathrm{T} 3$ & 351 & $85.2 \%$ & & \\
\hline $\mathrm{T} 4$ & 1670 & $63.5 \%$ & & \\
\hline $\mathrm{N}$ stage & & & 51.193 & $<0.001$ \\
\hline N1 & 1296 & $74.3 \%$ & & \\
\hline N2 & 960 & $60.3 \%$ & & \\
\hline Chemotherapy & & & 26.049 & $<0.001$ \\
\hline Yes & 2138 & $70.3 \%$ & & \\
\hline No & 118 & $46.8 \%$ & & \\
\hline No. of LNs dissected & & & 14.820 & $<0.001$ \\
\hline$<12$ & 469 & $60.9 \%$ & & \\
\hline$\geq 12$ & 1787 & $70.7 \%$ & & \\
\hline \multicolumn{5}{|l|}{ Negative/positive LNs ratio } \\
\hline two groups & & & 118.677 & $<0.001$ \\
\hline$\leq 2.38$ & 821 & $54.4 \%$ & & \\
\hline$>2.38$ & 1435 & $76.8 \%$ & & \\
\hline three group & & & 162.188 & $<0.001$ \\
\hline$\leq 0.55$ & 246 & $40.0 \%$ & & \\
\hline $0.55-2.38$ & 575 & $60.3 \%$ & & \\
\hline$>2.38$ & 1435 & $76.8 \%$ & & \\
\hline
\end{tabular}


Table 2: Multivariate survival analyses for evaluating prognostic factors influencing colorectal cancer cause specific survival.

\begin{tabular}{|c|c|c|c|c|}
\hline Variable & HR(95\%CI) & $P$ & HR(95\%CI) & $P$ \\
\hline Age & & $<0.001$ & & $<0.001$ \\
\hline$\leq 60$ & Reference & & Reference & \\
\hline$>60$ & $1.496(1.231-1.819)$ & & $1.526(1.255-1.856)$ & \\
\hline Pathological grading & & 0.001 & & 0.009 \\
\hline Well/ Moderate & Reference & & Reference & \\
\hline Poor/ Anaplastic & $1.517(1.219-1.889)$ & & $1.423(1.137-1.781)$ & \\
\hline Unknown & $1.308(0.824-2.077)$ & & $1.268(0.799-2.011)$ & \\
\hline Histological Type & & 0.709 & & 0.489 \\
\hline Adenocarcinoma & Reference & & Reference & \\
\hline Mucinous/Signet ring cell & $0.950(0.726-1.244)$ & & $0.909(0.693-1.191)$ & \\
\hline T stage & & $<0.001$ & & $<0.001$ \\
\hline $\mathrm{T} 1$ & Reference & & Reference & \\
\hline $\mathrm{T} 2$ & $1.512(0.353-6.481)$ & & $1.492(0.348-6.394)$ & \\
\hline $\mathrm{T} 3$ & $1.392(0.331-5.854)$ & & $1.404(0.334-5.902)$ & \\
\hline $\mathrm{T} 4 \mathrm{a}$ & $3.155(0.782-12.734)$ & & $3.053(0.757-12.323)$ & \\
\hline $\mathrm{T} 4 \mathrm{~b}$ & $5.070(1.192-21.562)$ & & 4.851(1.141-20.630) & \\
\hline $\mathrm{N}$ stage & & 0.872 & & 0.516 \\
\hline N1 & Reference & & Reference & \\
\hline N2 & $0.975(0.717-1.325)$ & & $0.900(0.656-1.235)$ & \\
\hline \multicolumn{5}{|l|}{ No. of LNs dissected } \\
\hline$<12$ & Reference & 0.009 & Reference & 0.016 \\
\hline$\geq 12$ & $0.730(0.577-0.923)$ & & $0.750(0.594-0.947)$ & \\
\hline Adjuvant chemotherapy & & $<0.001$ & & $<0.001$ \\
\hline Yes & Reference & & Reference & \\
\hline No & $1.930(1.407-2.648)$ & & $1.937(1.411-2.659)$ & \\
\hline NPR(two group) & & $<0.001$ & & \\
\hline $\mathrm{N}_{\mathrm{NPR}} 1(>2.38)$ & Reference & & & \\
\hline $\mathrm{N}_{\mathrm{NPR}} 2(\leq 2.38)$ & 2.335(1.717-3.176) & & & \\
\hline NPR(three group) & & & & $<0.001$ \\
\hline $\mathrm{N}_{\mathrm{NPR}} 1(>2.38)$ & & & Reference & \\
\hline $\mathrm{N}_{\mathrm{NPR}} 2(0.55-2.38)$ & & & $2.136(1.551-2.941)$ & \\
\hline $\mathrm{N}_{\mathrm{NPR}} 3(\leq 0.55)$ & & & $3.517(2.407-5.138)$ & \\
\hline
\end{tabular}

a: HR, hazard ratio; CI, confidence interval. 
Table 3: Subgroup analysis for evaluating the effect of NPR on survival according to N stage

\begin{tabular}{|l|l|l|l|l|l|}
\hline Variable & No. & 5-year CCSS & HR & 95\%CI & P \\
\hline N1 stage & & & & & \\
\hline $\mathbf{N}_{\text {NPR }}$ (two group) & & & & & \\
\hline$\leq 2.38$ & 1198 & $76.6 \%$ & 1.000 & Reference & \\
\hline$>2.38$ & 98 & $49.9 \%$ & 0.406 & $0.252-0.654$ & \\
\hline $\mathbf{N}_{\text {NPR }}$ (three group) & & & & & 0.001 \\
\hline$>2.38$ & 1198 & $76.6 \%$ & 0.390 & $0.240-0.633$ & \\
\hline $0.55-2.38$ & 91 & $48.1 \%$ & 1.000 & Reference & \\
\hline$\leq 0.55$ & 7 & $66.7 \%$ & 0.581 & $0.137-2.467$ & \\
\hline $\mathbf{N} 2$ stage & & & & & \\
\hline $\mathbf{N}_{\text {NPR }}$ (two group) & & & & & $<0.001$ \\
\hline$\leq 2.38$ & 237 & $77.3 \%$ & 1.000 & Reference & \\
\hline$>2.38$ & 723 & $55.0 \%$ & 0.448 & $0.295-0.683$ & \\
\hline $\mathbf{N}_{\text {NPR }}$ (three group) & & & & & $<0.001$ \\
\hline$>2.38$ & 237 & $77.3 \%$ & 0.529 & $0.343-0.817$ & \\
\hline $0.55-2.38$ & 484 & $62.8 \%$ & 1.000 & Reference & \\
\hline$\leq 0.55$ & 239 & $38.9 \%$ & 1.744 & $1.308-2.323$ & \\
\hline
\end{tabular}

$P$ values refer to comparison between each group to reference group and were adjusted for age, pathological grading, tumor histotype, T stage, No. of LNs dissected, adjuvant chemotherapy as covariates.

2. HR, hazard ratio; CI, confidence interval

Table 4: Cross-tabulation of the TNM and $\mathrm{TN}_{\mathrm{NPR}} \mathrm{M}$ staging system

\begin{tabular}{|c|c|c|c|c|c|}
\hline & & \multicolumn{3}{|c|}{$\mathbf{T N}_{\mathrm{NPR}} \mathrm{M}$ Stage } & \multirow[t]{2}{*}{ Total } \\
\hline & & IIIA & IIIB & IIIC & \\
\hline TNM stage & IIIA & 162 & 10 & 0 & 172 \\
\hline IIIB & & 21 & 1148 & 65 & 1234 \\
\hline IIIC & & 0 & 194 & 656 & 850 \\
\hline Total & & 183 & 1352 & 721 & \\
\hline
\end{tabular}

than those at $\mathrm{N} 1+\mathrm{NPR} \leq 2.38$ and $\mathrm{N} 2+\mathrm{NPR} \leq 2.38$ stage $(P<0.001)$. The different between $\mathrm{N} 1+\mathrm{NPR} \leq 2.38$ and $\mathrm{N} 2+\mathrm{NPR} \leq 2.38$ stage was also not significance $(\chi 2=$ $0.290, P=0.590$ ) (Figure 3).

\section{Comparison of prognostic prediction accuracies between the TNM and TN $\mathrm{NPR}_{\text {M stage }}$ classifications}

We defined the $\mathrm{TN}_{\mathrm{NPR}} \mathrm{M}$ system in reference with the current TNM stage, that T1-2 $\mathrm{N}_{\mathrm{NPR}} 1, \mathrm{~T} 1 \mathrm{~N}_{\mathrm{NPR}} 2$ were defined as IIIA, T3-4 $\mathrm{N}_{\mathrm{NPR}} 1, \mathrm{~T} 2-3 \mathrm{~N}_{\mathrm{NPR}} 2, \mathrm{~T} 1-2 \mathrm{~N}_{\mathrm{NPR}} 3$ were defined as IIIB, T4 $\mathrm{aN}_{\mathrm{NPR}} 2$, T3-4aN $\mathrm{NPR}_{\mathrm{N}} 3, \mathrm{~T} 4 \mathrm{~b} \mathrm{~N}_{\mathrm{NPR}} 1-3$ were defined as IIIC. Table 4 presents classification for both the current TNM and $\mathrm{TN}_{\mathrm{NPR}} \mathrm{M}$ stage systems. Statistical assessment of the prognostic performance of the stage systems by the c-index revealed a value of $0.659(95 \% \mathrm{CI}: 0.634-$ 0.683 ) for $\mathrm{TN}_{\mathrm{NPR}} \mathrm{M}$, which was significantly better than 0.628(95\%CI:0.603-0.652) for TNM $(P<0.001)$.

\section{DISCUSSION}

Adequate LNs evaluation is required for accurate staging of $\mathrm{CRC}$, and the number of $\mathrm{LNs}$ retrieval is a predictor in CRC after surgical resection. Lower LN evaluation is associated with worse survival outcome in terms of tumor recurrence and overall survival rate [46]. In stage III CRC, the total LNs are composed of both metastases LNs and negative LNs. The number of positive LNs is used as an important factor in current TNM stage and is associated with survival outcome for patients with CRC [18]. Our previous study also indicated that negative LNs was an independently prognosis factor in CRC. However, most of previous study did not consider both NLNs and PLNs simultaneously. More recently, some researchers have demonstrated the lymph node ratio (LNR) was a better indicator of prognosis rather than the number of metastatic LNs alone [19-21].The assumption is that LNR accounts for both total lymph node retrieval, as well as the metastatic LNs number. However, higher weight is given to an LN metastasis when fewer overall LNs are retrieved [21].

Compared with the LNR, NPR is straight ratio between negative and positive LNs, which may serve as a better prognostic factor than PLNs, NLNs and LNR. In this study, NPR was validated as a risk factor for survival in CRC. In multivariate analysis, NPR remained 
an independent prognostic factor for CCSS, and the prognostic value of NPR remained significant in subgroup analysis of both N1 and N2 stage. Meanwhile, NPR also showed the greater log-rank $\chi 2$ value than current LN stage in stage III CRC. Importantly, C-index value is higher in $\mathrm{TN}_{\mathrm{NPR}} \mathrm{M}$ stage than TNM stage, indicating that NPR had the greatest statistical significance for the prognosis of CRC. Precise tumor staging is one of most important predictor determining the patient's survival outcome. In TNM staging system, the $\mathrm{N}$ stage is the most important marker of the CRC patient's prognosis, so we suggest that using $\mathrm{N}_{\mathrm{NPR}}$ stage instead of current $\mathrm{N}$ stage in stage III CRC, which could improve prognostic stratification.

NPR is more accurate because it takes into account both the PLNs and the NLNs, both of which has been validated to be important predictors, moreover, NPR is straight ratio between negative and positive LNs presents with several meanings. First, the number of metastasis LNs is directly associate with CRC patients' survival [18, 22]. Second, increasing NLNs retrieval can avoid stage- migration. The more LNs examined, the more likely that it reflects the true stage, and lower nodal counts may increase the risk of understaging. Third, NLNs is associate with the host immune response to cancer cells. The protective effect of NLNs may simply reflect a host lymphocytic reaction to the tumor, which is associated with $\mathrm{LN}$ count [23], and lymphocytic reaction to tumor cells has been correlated with prolong survival in CRC [24-26]. Fourth, the surgeon is a technician. It is possible that the patients who had higher number of LNs retrieved experienced more extensive excision of primary tumors and their draining nodes. Improved surgical techniques may also be the result of improved intraoperative staging [7] and to reduce the chances of iatrogenic spread of cancer cells. Then, the possibility of leaving tumor cells behind is low, which may have positively effect on survival. A high NLNs count may be an indicator of perfect surgical care or pathological examination. By increasing NLN counts, the chance of micrometastasis remaining within NLNs, which is a proven prognostic factor [27], may decrease.
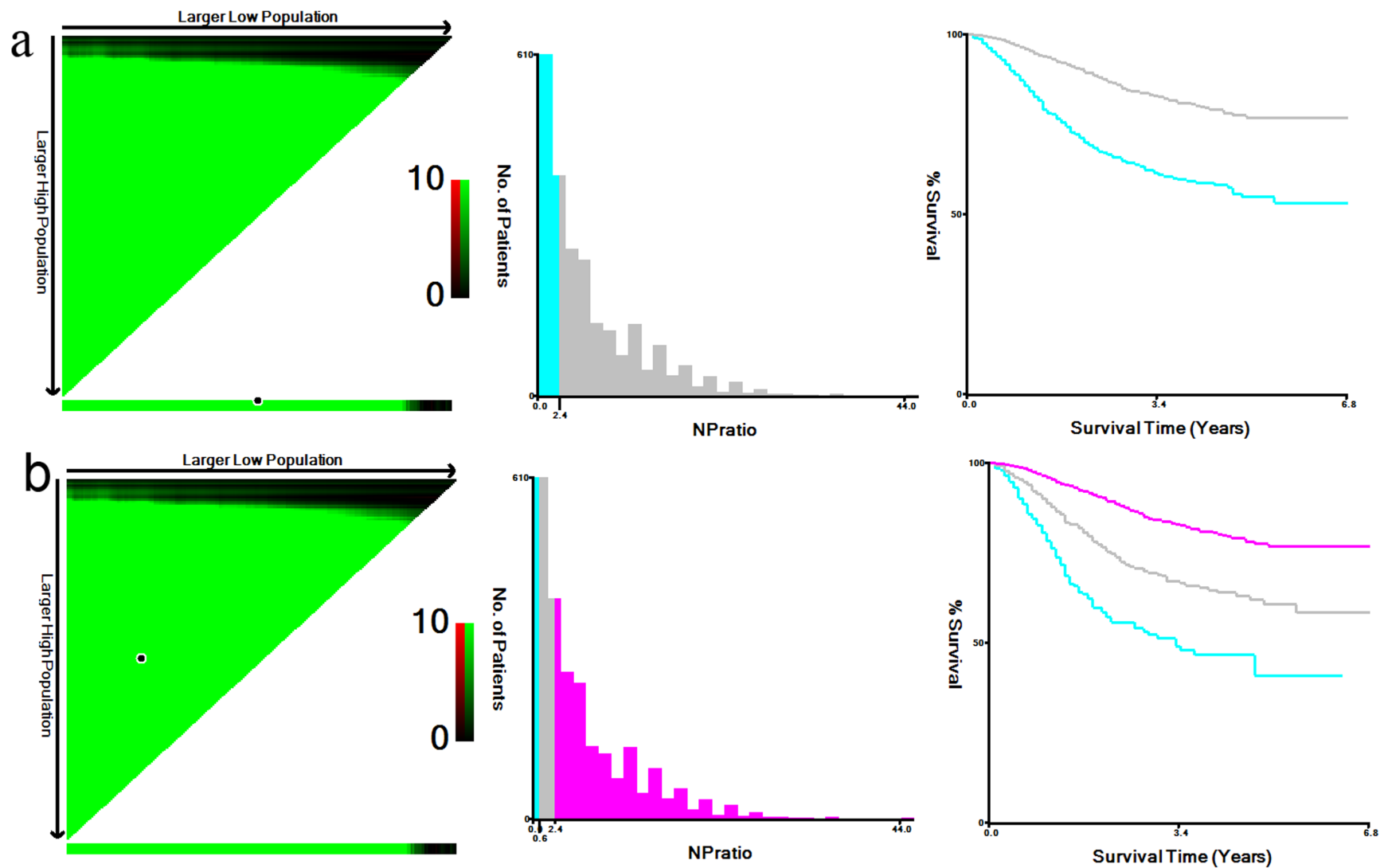

Figure 1: X-tile analysis of survival data from Fudan university Shanghai cancer center (FUSCC). X-tile analysis was done on patient data from FUSCC, equally divided into training and validation sets. X-tile plots of training sets are shown in the left panels, with plots of matched validation sets shown in the smaller inset. The optimal cut-point highlighted by the black circle in the left panels is shown on a histogram of the entire cohort (middle panels), and a Kaplan-Meier plot (right panels). P values were determined by using the cut-point defined in the training set and applying it to the validation set. Figures shows a. the maximum of $\chi 2$ log-rank values of $118.677(p$ $<0.001)$ was achieved when applying the number of 2.38 as the cutoff value for NPR to divide patients into high and low group; b. the maximum log-rank statistical value was 162.188 when the cutoff value were $0.55 / 2.38(p<0.001)$ for NPR. To divide patients into high, middle and low risk group. 
Certainly, our study has several limitations. One of these is LN retrieval depends on multiple factors varying from surgeon's experience, techniques of LNs harvest individual surgeons, pathologists, and other factors, but we cannot adjust for these factors. However, this could be compensated for our center is one of the highest volume colorectal surgery units in China. All surgeons included in present study have received formal training in TME, and our Department of Pathology is the quality control center in Shanghai city. Every specimen was examined
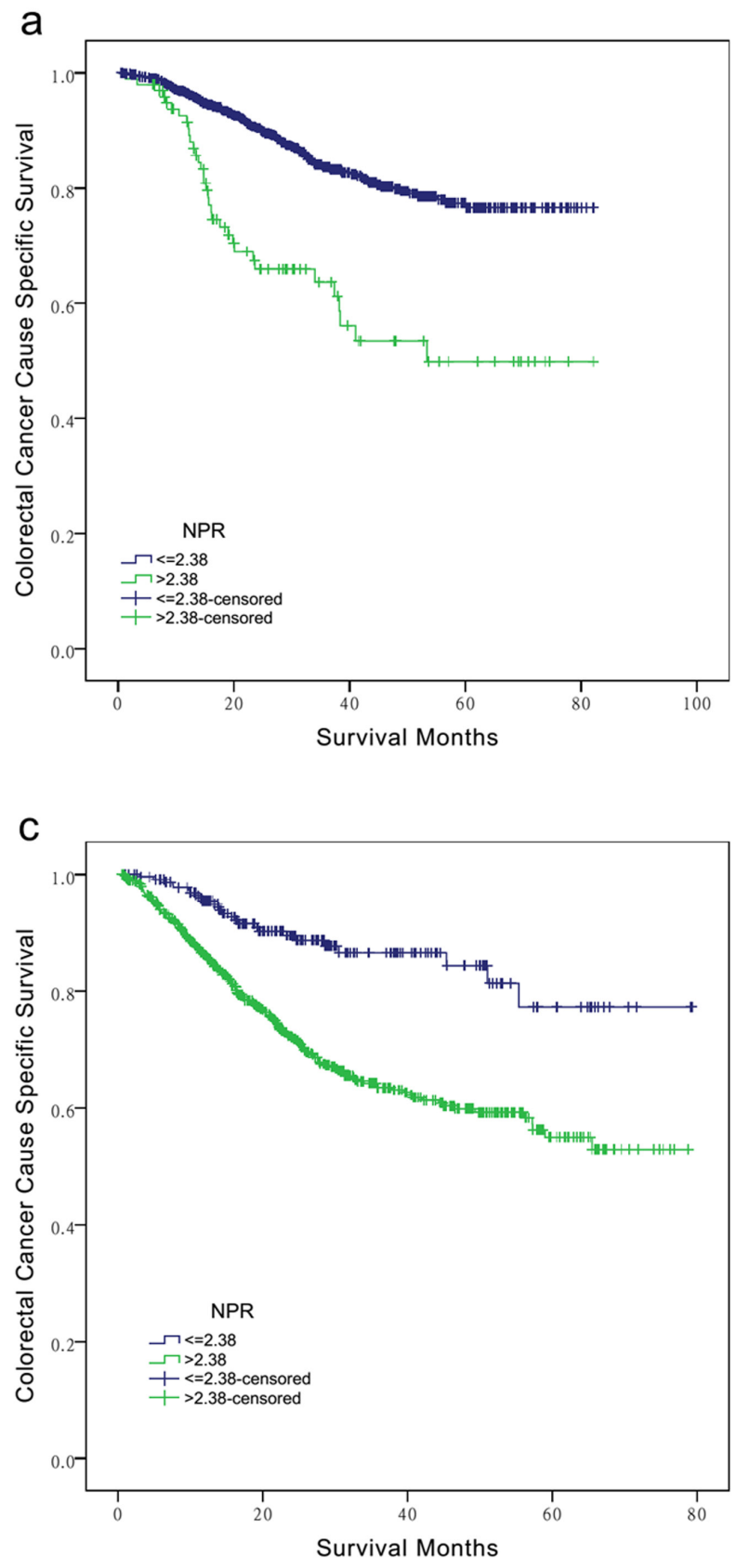

by two pathologists. Another is adjuvant therapy was only dichotomized as performed or not. The reagents and therapy cycles may affect survival as well.

In conclusion, our study shows that the NPR was an independent prognostic factor for stage III CRC patients, it could provide more accurate prognostic information than the current node stage system.
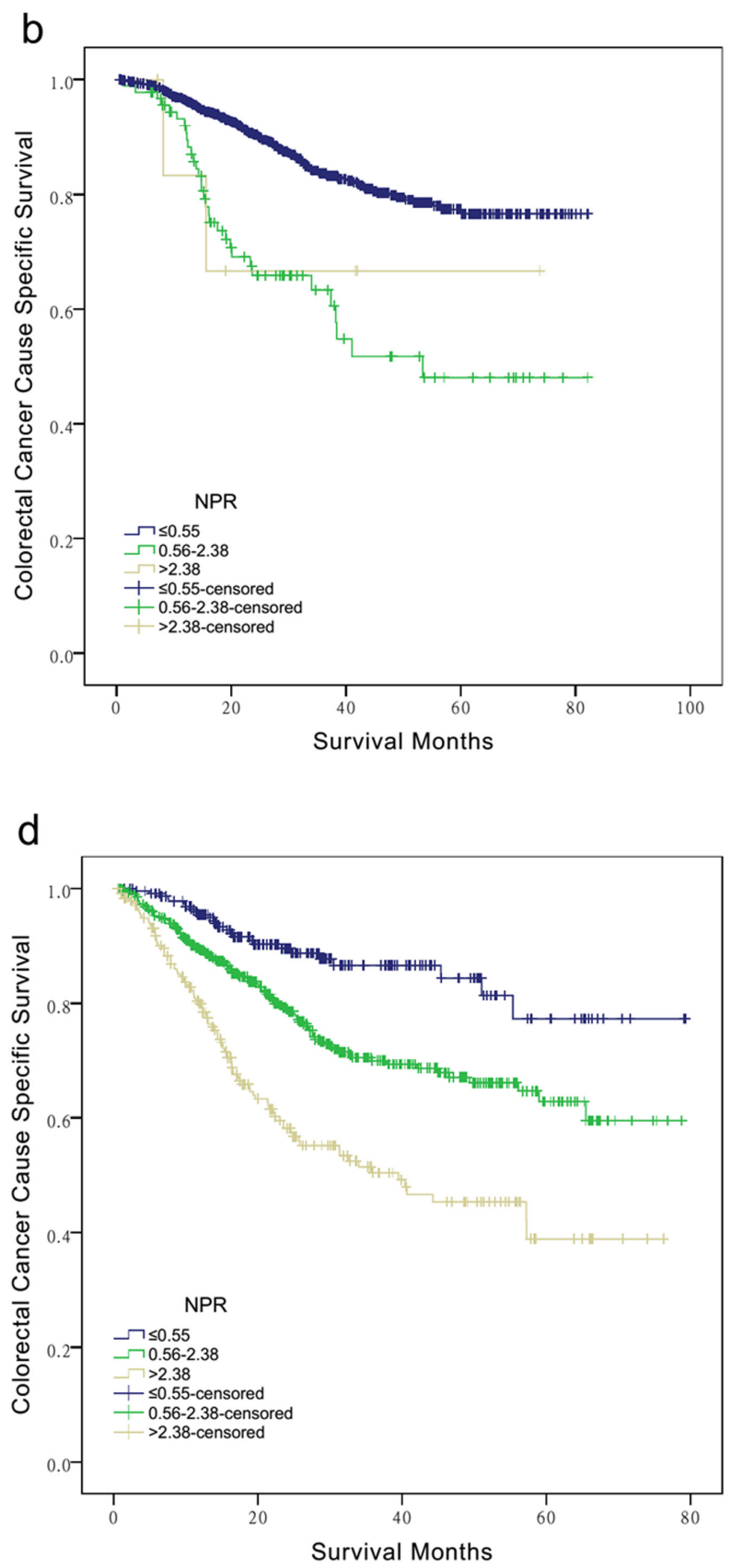

Figure 2: Subgroup analysis for evaluating the effect of $\mathbf{N}_{\mathrm{NPR}}$ stage according $\mathbf{N}$ classification for colorectal cancer patients at III stage. For patients at N1 stage, a. NPR $>2.38 V S \leq 2.38, \chi 2=38.552, P<0.001$. b. NPR $\leq 0.55,0.55-2.38$ and $>2.38$, $\chi 2=38.879, P<0.001$. For patients at N2 stage, c. NPR $>2.38 V S \leq 2.38, \chi 2=28.579, P<0.001$. d. NPR $\leq 0.55,0.55-2.38$ and $>2.38$, $\chi 2=62.401, P<0.001$. 


\section{MATERIALS AND METHODS}

\section{Patients}

The Fudan University Shanghai Cancer Center (FUSCC) CRC dataset was built prospectively and recorded the CRC patients treated at FUSCC, Shanghai, China since January, 2006. The records of patients with CRC who were treated at the FUSCC between January 2007 and December 2012 were retrospectively analyzed. Criteria for inclusion in the analysis were: (1) pathologically confirmed invasive CRC; (2) Received radical resection; (3) At least $1 \mathrm{LNs}$ retrieval, and pathologic diagnosed as stage III patients; (4) CRC as a single primary tumor; and (5) age $>18$ years old. Patients who received neoadjuvant therapy or died within 30 days after surgery were excluded from this study.

The research protocol was reviewed and approved by the Ethical Committee and Institutional Review Board of the FUSCC. All patients provided written consent for storage of their information in the hospital database, and for the research use of the information.

\section{Surgical management and follow up}

All the patients underwent curative colorectal tumor resection plus lymphadenectomy. The standard surgical treatment for colon cancer is resection of the tumor and its mesentery with primary anastomosis. The precise extent of the resection depends on the location of the tumors and its arterial supply. The procedure of rectal cancer is performed as previously described [28]. All patients were asked to follow-up every 3-6 months at the Colorectal Cancer Center in the first 3 years after surgery by their operating surgical team, and every 6-12 months thereafter. Postoperative follow-up protocol included general physical examinations, digital rectal examination, and routine laboratory tests. Chest $\mathrm{X}$-rays were performed every 6 months, and abdominal/pelvic $\mathrm{CT}$ and colonoscopy were performed every 6-12 months for the first 3 years. Surviving patients were followed-up between March and May 2015.

\section{Statistical analysis}

Demographic and clinical variables including age, sex, tumor location, depth of tumor invasion, total number of LNs examined, number of involved LNs, grade, histotype, overall survival time, and cancer specific death were retrieved from FUSCC database. The TNM stages were restaged according to the 7th edition of AJCC/UICC staging system. The number of NLNs was obtained by subtracting the number of positive LNs from the total number of removed LNs. The NPR defined as the ratio of the number of NLNs to the number of positive LNs.

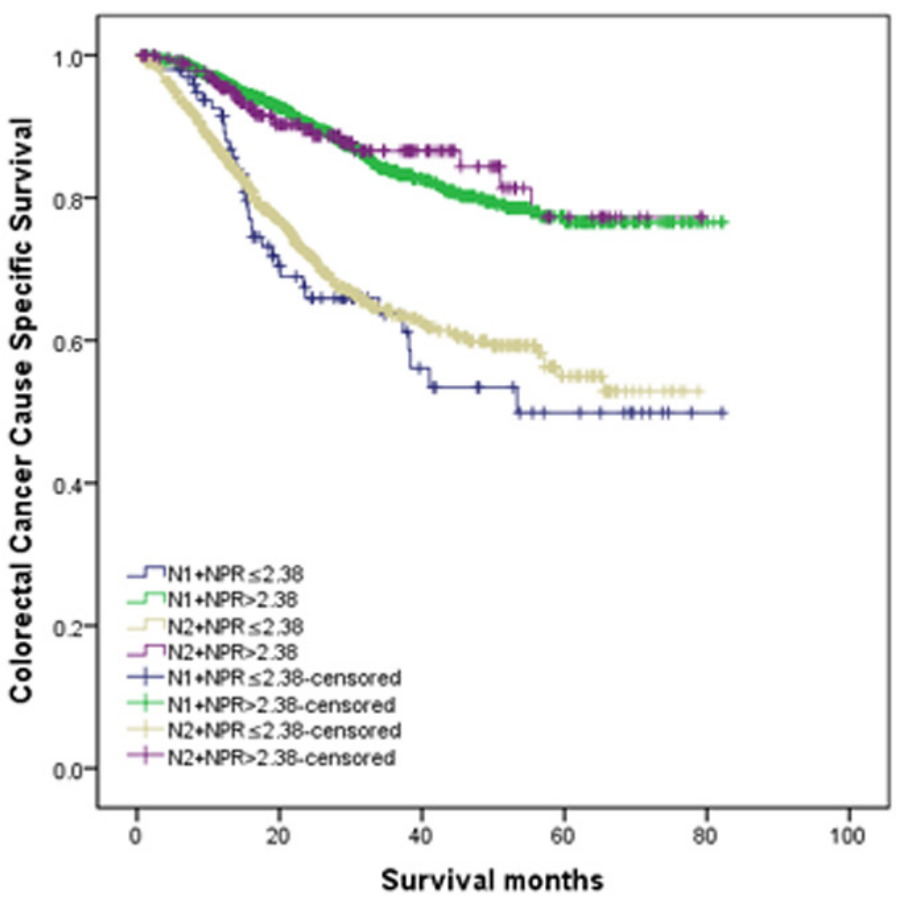

Figure 3: Combined analysis of $\mathbf{N}$ stage and $\mathbf{N}_{\mathbf{N P R}}$ stage. Patients in N2+ NPR $>2.38$ stage have similar survival outcome with N1+ NPR $>2.38$ stage $(\chi 2=0.030, P=0.863)$, and better than those at N1+ NPR $\leq 2.38$ and N2+ NPR $\leq 2.38$ stage $(p<0.001)$. The different between $\mathrm{N} 1+\mathrm{NPR} \leq 2.38$ and $\mathrm{N} 2+\mathrm{NPR} \leq 2.38$ stage was also not significance $(\chi 2=0.290, P=0.590)$. 
The NPR cutoff points were analyzed using the X-tile program (http://www.tissuearray.org/rimmlab/), which identified the cutoff with the minimum $\mathrm{P}$ values from log-rank $\chi 2$ statistics for the categorical NPR in terms of survival [29]. The relationship between various clinical and histological variables and survival was evaluated using the Kaplan-Meier method. Differences between survival curves were tested for statistical significance by using log rank test. The Cox proportional hazard regression model was used to identify the variables that could independently influence survival in CRC patients. The chi-square test was used for categorical variables. The 5-year colorectal cancer cause specific survival (CCSS) rate was estimated from Kaplan-Meier curves. Deaths attributed to the CRC of interest are treated as events and deaths from other causes are treated as censored observation.

The Harrell's concordance index(C-index $)$ were used to compare the staging systems [30]. The C-index is a measure of discrimination used to evaluate whether a staging system can discriminate between two patients at different stages of disease. It is calculated as the probability that for a random pair of patients at different stages of disease, the patient at the lower stage has a longer observed survival. The range of the $\mathrm{C}$-index is 0 to 1,1 indicating a perfect discrimination, whereas 0.5 indicating no better concordance than chance, 0 indicating perfect discordance. The larger the $\mathrm{C}$-index, the more accurate was the prognostic prediction [31]. Statistical analyses were performed with the statistical software package SPSS (Statistical Package for the Social Sciences) for Windows, version 17 (SPSS Inc, Chicago, IL, USA) and $\mathrm{R}$ (a language and environment for statistical computing) Version 3.0.2 for Mac (R Foundation for Statistical Computing, Vienna, Austria). Two-sided p values of less than 0.05 were considered to be statistically significant.

\section{ACKNOWLEDGMENTS}

The authors acknowledge the efforts of the Surveillance, Epidemiology, and End Results (SEER) Program tumor registries in the creation of the SEER database. The interpretation and reporting of these data are the sole responsibility of the authors. This study was partially supported by grants from the National Natural Science Foundation of China (No. 81001055, 81101586), and National Key Basic Research Program of China (2014CBA02002).

\section{CONFLICTS OF INTEREST} declare.

\section{Author Contributions}

QGL, JZ, and SJC conceived of and designed the study. LL and HXJ performed the analyses. XXL and YX prepared all figures and tables. QGL, LL, JZ, and SJC wrote the main manuscript. All authors reviewed the manuscript.

\section{REFERENCES}

1. Siegel RL, Miller KD and Jemal A. Cancer statistics, 2015. CA Cancer J Clin. 2015; 65:5-29.

2. Wan DS. [Epidemiologic trend of and strategies for colorectal cancer]. Ai Zheng. 2009; 28:897-902.

3. Zou L, Zhong R, Lou J, Lu X, Wang Q, Yang Y, Xia J, Ke J, Zhang T, Sun Y, Liu L, Cui Y, Xiao H, Chang L, Xia $\mathrm{D}$ and $\mathrm{Xu} \mathrm{H}$. Replication study in Chinese population and meta-analysis supports association of the 11q23 locus with colorectal cancer. PLoS One. 2012; 7:e45461.

4. Kim YW, Kim NK, Min BS, Lee KY, Sohn SK and Cho $\mathrm{CH}$. The influence of the number of retrieved lymph nodes on staging and survival in patients with stage II and III rectal cancer undergoing tumor-specific mesorectal excision. Ann Surg. 2009; 249:965-972.

5. Tepper JE, O’Connell MJ, Niedzwiecki D, Hollis D, Compton C, Benson AB, 3rd, Cummings B, Gunderson L, Macdonald JS and Mayer RJ. Impact of number of nodes retrieved on outcome in patients with rectal cancer. J Clin Oncol. 2001; 19:157-163.

6. Xingmao Z, Hongying $\mathrm{W}$, Zhixiang $\mathrm{Z}$ and Zheng $\mathrm{W}$. Analysis on the correlation between number of lymph nodes examined and prognosis in patients with stage II colorectal cancer. Med Oncol. 2013; 30:371.

7. Le Voyer TE, Sigurdson ER, Hanlon AL, Mayer RJ, Macdonald JS, Catalano PJ and Haller DG. Colon cancer survival is associated with increasing number of lymph nodes analyzed: a secondary survey of intergroup trial INT0089. J Clin Oncol. 2003; 21:2912-2919.

8. Vather R, Sammour T, Zargar-Shoshtari K, Metcalf P, Connolly A and Hill A. Lymph node examination as a predictor of long-term outcome in Dukes B colon cancer. Int J Colorectal Dis. 2009; 24:283-288.

9. Chen SL and Bilchik AJ. More extensive nodal dissection improves survival for stages I to III of colon cancer: a population-based study. Ann Surg. 2006; 244:602-610.

10. Caplin S, Cerottini JP, Bosman FT, Constanda MT and Givel JC. For patients with Dukes' B (TNM Stage II) colorectal carcinoma, examination of six or fewer lymph nodes is related to poor prognosis. Cancer. 1998; 83:666672.

11. Prandi M, Lionetto R, Bini A, Francioni G, Accarpio G, Anfossi A, Ballario E, Becchi G, Bonilauri S, Carobbi A, Cavaliere P, Garcea D, Giuliani L, et al. Prognostic evaluation of stage $\mathrm{B}$ colon cancer patients is improved 
by an adequate lymphadenectomy: results of a secondary analysis of a large scale adjuvant trial. Ann Surg. 2002; 235:458-463.

12. Sarli L, Bader G, Iusco D, Salvemini C, Mauro DD, Mazzeo A, Regina $G$ and Roncoroni L. Number of lymph nodes examined and prognosis of TNM stage II colorectal cancer. Eur J Cancer. 2005; 41:272-279.

13. Johnson PM, Porter GA, Ricciardi R and Baxter NN. Increasing negative lymph node count is independently associated with improved long-term survival in stage IIIB and IIIC colon cancer. J Clin Oncol. 2006; 24:3570-3575.

14. Deng J, Liang H, Wang D, Sun D, Ding X, Pan Y and Liu $\mathrm{X}$. Enhancement the prediction of postoperative survival in gastric cancer by combining the negative lymph node count with ratio between positive and examined lymph nodes. Ann Surg Oncol. 2010; 17:1043-1051.

15. Zhu Z, Chen H, Yu W, Fu X, Xiang J, Li H, Zhang Y, Sun M, Wei Q, Zhao W and Zhao K. Number of Negative Lymph Nodes is Associated with Survival in Thoracic Esophageal Squamous Cell Carcinoma Patients Undergoing Three-Field Lymphadenectomy. Ann Surg Oncol. 2014.

16. Chen Y, Zhang L, Tian J, Ren X and Hao Q. Combining the negative lymph nodes count with the ratio of positive and removed lymph nodes can better predict the postoperative survival in cervical cancer patients. Cancer Cell Int. 2013; 13:6.

17. Li Q, Zhuo C, Cai G, Li D, Liang L and Cai S. Increased number of negative lymph nodes is associated with improved cancer specific survival in pathological IIIB and IIIC rectal cancer treated with preoperative radiotherapy. Oncotarget. 2014; 5:12459-12471. doi: 10.18632/ oncotarget. 2560 .

18. Li Q, Wang Y, Cai G, Li D and Cai S. Solitary lymph node metastasis is a distinct subset of colon cancer associated with good survival: a retrospective study of surveillance, epidemiology, and end-results population-based data. BMC Cancer. 2014; 14:368.

19. Kim YS, Kim JH, Yoon SM, Choi EK, Ahn SD, Lee SW, Kim JC, Yu CS, Kim HC, Kim TW and Chang HM. lymph node ratio as a prognostic factor in patients with stage III rectal cancer treated with total mesorectal excision followed by chemoradiotherapy. Int J Radiat Oncol Biol Phys. 2009; 74:796-802.

20. Hong KD, Lee SI and Moon HY. Lymph node ratio as determined by the 7th edition of the American Joint Committee on Cancer staging system predicts survival in stage III colon cancer. J Surg Oncol. 2011; 103:406-410.

21. Gleisner AL, Mogal H, Dodson R, Efron J, Gearhart S, Wick E, Lidor A, Herman JM and Pawlik TM. Nodal status, number of lymph nodes examined, and lymph node ratio: what defines prognosis after resection of colon adenocarcinoma? J Am Coll Surg. 2013; 217:1090-1100.
22. Gunderson LL, Jessup JM, Sargent DJ, Greene FL and Stewart AK. Revised TN categorization for colon cancer based on national survival outcomes data. J Clin Oncol. 2010; 28:264-271.

23. George S, Primrose J, Talbot R, Smith J, Mullee M, Bailey D, du Boulay C and Jordan H. Will Rogers revisited: prospective observational study of survival of 3592 patients with colorectal cancer according to number of nodes examined by pathologists. Br J Cancer. 2006; 95:841-847.

24. Pages F, Galon J and Fridman WH. The essential role of the in situ immune reaction in human colorectal cancer. J Leukoc Biol. 2008; 84:981-987.

25. Morris M, Platell C and Iacopetta B. Tumor-infiltrating lymphocytes and perforation in colon cancer predict positive response to 5-fluorouracil chemotherapy. Clin Cancer Res. 2008; 14:1413-1417.

26. Ogino S, Nosho K, Irahara N, Shima K, Baba Y, Kirkner GJ, Mino-Kenudson M, Giovannucci EL, Meyerhardt JA and Fuchs CS. Negative lymph node count is associated with survival of colorectal cancer patients, independent of tumoral molecular alterations and lymphocytic reaction. Am J Gastroenterol. 2010; 105:420-433.

27. Rahbari NN, Bork U, Motschall E, Thorlund K, Buchler MW, Koch M and Weitz J. Molecular detection of tumor cells in regional lymph nodes is associated with disease recurrence and poor survival in node-negative colorectal cancer: a systematic review and meta-analysis. J Clin Oncol. 2012; 30:60-70.

28. Cai SJ, Xu Y, Cai GX, Lian P, Guan ZQ, Mo SJ, Sun MH, Cai Q and Shi DR. Clinical characteristics and diagnosis of patients with hereditary nonpolyposis colorectal cancer. World J Gastroenterol. 2003; 9:284-287.

29. Camp RL, Dolled-Filhart M and Rimm DL. X-tile: a new bio-informatics tool for biomarker assessment and outcomebased cut-point optimization. Clin Cancer Res. 2004; 10:7252-7259.

30. Steyerberg EW, Vickers AJ, Cook NR, Gerds T, Gonen M, Obuchowski N, Pencina MJ and Kattan MW. Assessing the performance of prediction models: a framework for traditional and novel measures. Epidemiology. 2010; 21:128-138.

31. Koerkamp BG, Wiggers JK, Allen PJ, Busch OR, D'Angelica MI, DeMatteo RP, Fong Y, Gonen M, Gouma DJ, Kingham TP, van Gulik TM and Jarnagin WR. American Joint Committee on Cancer staging for resected perihilar cholangiocarcinoma: a comparison of the 6th and 7th editions. HPB (Oxford). 2014; 16:1074-1082. 